\title{
Global trends in the improvement of combine harvesters
}

\author{
V.Ya. Goltyapin, I.G. Golubev*, and D.S. Buklagin
}

FSBSI "Russian Research Institute of Information and Technical and Economic Research on Engineering and Technical Support of the Agro-Industrial Complex", Russian Federation

\begin{abstract}
It is noted that the use of foreign experience and achievements in the design of domestic machines is one of the effective tools to accelerate the development of agricultural technologies and equipment. The directions of combine harvester improvement and innovations in their designs are given. It was revealed that the most powerful engines (maximum power of $581 \mathrm{~kW}$ ) are installed on the combine harvesters "Ideal 10" (Fendt company) and "Lexion 8900 Terra Trac" (Claas company). It is shown that the engine power of the most high-performance combine harvesters reached $581 \mathrm{~kW}$. According to the toxicity of exhaust gases, they meet modern requirements. It is found that the technology of selective catalytic reduction SCR is increasingly used in the designs of combine harvesters. They allow to reduce the emissions of toxic substances into the environment by 2-3 times and reduce fuel costs by $40 \%$, as well as the use of natural gas as fuel. It is revealed that the efficiency of using combine harvesters is increased by improving the engines, threshing devices, separation, cleaning, thresher loading and process control systems, working bodies of headers and cutters.
\end{abstract}

\section{Introduction}

The use of foreign experience and achievements in the design of domestic machines is one of the effective tools to accelerate the development of agricultural technologies and equipment. The world's largest exhibition of agricultural machinery "Agritechnica" has welldeserved authority with agricultural producers, agricultural machine builders, scientific community and business. In 2019, the exhibition was held under the slogan "Global Farming - Local Responsibility" [2]. The main thematic trends were environmental concern, preservation of a favorable environmental situation, technical innovations and technological solutions to improve the work of agricultural farms of any format. Among the novelties of agricultural machinery for various purposes, a significant place at the exhibition was occupied by combine harvesters.

\footnotetext{
${ }^{*}$ Corresponding author: golubev@rosinformagrotech.ru
} 


\section{Materials and methods}

The analysis was carried out using the brochures and other information materials of the exhibition participants, processing and analysis of information from foreign magazines, exhibition websites (www.agritechnica.com) and machine manufacturers, the results of the analysis of trends in the development of combine harvesters, carried out by specialists of the German Agricultural Society (DLG).

\section{Results and discussion}

The analysis showed that the combine harvesters presented at the exhibition are equipped with engines that meet modern requirements for exhaust gas toxicity. As with tractors, their design increasingly uses SCR selective catalytic reduction technology. The most powerful engines (maximum power of $581 \mathrm{~kW}$ ) are installed on the combine harvesters "Ideal 10" (Fendt company) and "Lexion 8900 Terra Trac" (Claas company) [1-3].

The innovative development of the company "Fendt" is of interest, which replaced the steering wheel with the IDEALDrive control system on the model "Ideal 10" using a joystick located on the left armrest, which provides a better view of the header and when driving on the highway [4]. In addition to controlling the harvester, IDEALdrive provides management of various functions. In addition to turning on the indicators, low beam/high beam and beep, the joystick also has a button to turn on the lane guidance. The armrest can be folded back to make it easier to sit on the seat. The system complies with the European standards for vehicles and traffic regulations. The threshing and separating device on the combine harvester is tworotor. The vegetable mass is fed to the rotors by a feeder drum with a diameter of $600 \mathrm{~mm}$. The speed of its rotation is $70 \%$ of the rotors' speed and is synchronized with them. Along the length of the rotor, there are four zones for processing the bread mass: feeding, threshing, separation and unloading. The front part of the rotors consists of four longitudinally mounted impact beams that separate the grain from the ears. The working elements of the rotors (rods and fingers) are arranged in a spiral in four rows. The distance between the rotor and the concave is adjusted by a hydraulic drive, its maximum value is $35 \mathrm{~mm}$. Depending on the application conditions, the concave can be replaced on the side of the combine harvester housing. The teeth of the rotor are tilted $20^{\circ} \mathrm{back}$, so that the material is distributed on the spiral sections and in a gentle mode moves along and around the rotor. This solution eliminates the possibility of unexpected loads on the rotor and the appearance of areas in which the material can get stuck. The next innovation on the combine harvester: to receive the threshed heap, the IDEALbalance technology is used, which is based on a double grain board. Grain is fed to the front grain board, threshed at the front of the rotors, which is then sent to the front of the shaking board. The material separated by the teeth of the rotor is appeared on the second (back) grain board, then the material falls into the back of the shaking board. In this way, the entire area of the shaking board is used evenly, which helps to improve grain cleaning. In addition, the front grain board is made caved-in, so that the grain is concentrated in the middle, and the back is convex, where the grain is collected at the edges (Fig. 1).

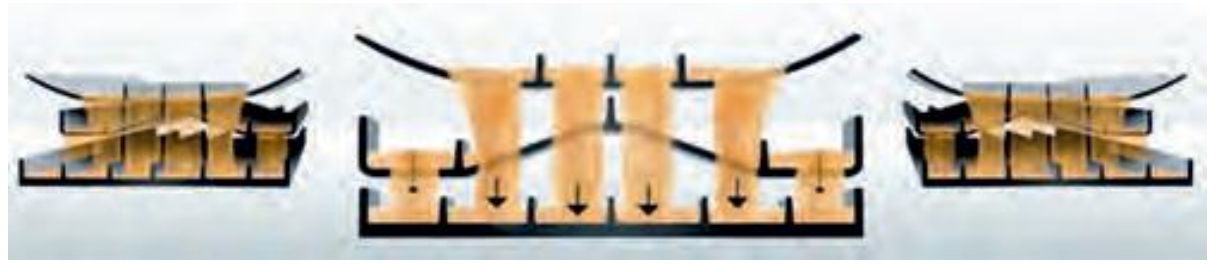

Fig. 1. Distribution of grain heaps by grain boards. 
Thanks to this, regardless of the harvesting conditions, a uniform distribution of the heap over the width is achieved. Compared to flat grain boards, this design on a $15^{\circ}$ slope reduces grain losses by $60 \%$. The combine harvester is equipped with the largest grain hopper on the market of combine harvesters. Its capacity is 17,100 liters $(+18 \%$ compared to modern highperformance harvesters). The capacity of the tank discharge auger is $210 \mathrm{l} / \mathrm{sec}$, which is $32 \%$ ahead of the nearest competitors in the market. At the same time, the ScrollSwing control system is used to evenly fill the vehicle body, and the driver does not have to constantly move forward and backward. The adjustment wheel on the multi-function joystick allows to gently move the discharge auger during unloading. In combination with the Streamer Gate hydraulic speed control system, a gentle unloading process is implemented. The combine harvester is equipped with unloading augers with a length of 7.6, 9.15 or $10.6 \mathrm{~m}$ (from the middle of the combine harvester). For the two longest variants, an additional folding is provided in the transport position behind the combine harvester. At the end of the auger there is a valve that prevents losses after the unloading process is completed. It is automatically opened and closed by a hydraulic cylinder. The automatic AutoDock attachment system allows to quickly attach the header to the harvester: all mechanical, electrical and hydraulic connections are installed from the cab by pressing a button on the terminal in 5 seconds. In this case an RFID code assigned to each header is used and it allows the harvester to automatically recognize which header to deal with. The RFID code allows to call up the latest settings used for the corresponding header in the Vario terminal menu (diagonal 10.4 inches), for example, dimensions and sensitivity parameters for automatic adjustment, which significantly reduces the load on the driver. The IDEALharvest system allows to display the loading status of the thresher and the cleaning system. The mass acoustic detectors/sensors (MAD) used in it, located along the rotors and the screen box, measure in real time both the volume of the harvested crop flow inside the machine and the grain loss. Supplemented with a grain quality control camera, MAD sensors inform about grain losses, the proportion of broken grain and its cleanliness. The graphic data displayed in real time on the iPad's display shows the driver which part of the thresher - front, rear, right or left - contains the most material. The SmartConnect app allows to create an individual cleaning strategy based on this data. The driver can choose from three harvesting strategies: minimizing damage, minimizing losses, and optimizing grain cleanliness. The slider also can be used to set the performance value. After that, the rotation speed of the rotors and the fan, the opening of the upper and lower sieves, as well as the speed of movement are adjusted according to the selected strategy.

The load regulators of the thresher of combine harvesters react to changes in the state of the grain mass already on the working bodies. In case of changes in the harvesting process, for example, yield level, plant height, weed area, appearance of a technological track or already harvested areas, the combine harvester is overloaded or insufficiently loaded. The John Deere company solved this problem by using a self-learning intelligent capacity management system that uses predictive data and harvested crop data [1, 5]. Threedimensional stereo cameras evaluate the condition of the harvested crop before the combine harvester. The stem height, the flattened crops with the direction of the flatness, the spaces, the presence of areas with a track and harvested areas are identified, then they are classified using the so-called Machine Learning. The system also uses data from vegetation models obtained from satellite biomass maps or other technical means. During the harvesting process, the system calculates a regression model in real time and based on vegetation data with reference to the geographical coordinate system. The system combines the received values and the strategy that the combine driver sets and changes the speed and settings depending on the situation. With this technology, Jthe ohn Deere company has taken a major step in the further development of grain harvesting automation.

The new X9 series of John Deere combine harvesters includes two models X9 1000 and X9 1100 with a capacity of 410 and $450 \mathrm{~kW}$, respectively. They are specially designed for 
difficult harvesting conditions. They are equipped with 6-cylinder PowerTech PSS engines with a working volume of 13.6 liters, hydraulic valve clearance compensation and meet the Stage V standard for the level of harmful substances in the exhaust gases. The ProDrive XL transmission on combine harvesters is continuously variable, providing $30 \%$ more torque on slopes and in high humidity conditions compared to the one used on previous models of combine harvesters. The transport speed of $40 \mathrm{~km} / \mathrm{h}$ is achieved at a reduced engine crankshaft speed (up to $1700 \mathrm{~min}-1$ ). The main novelty of the ProDrive XL transmission is two pumps that are activated simultaneously at start-up to provide maximum torque. When the demand decreases, the power of the second pump decreases. The combine harvesters are available in a full wheeled or semi-tracked version on crawler trucks with a triangular belt with a width of 76 to $91 \mathrm{~cm}$ instead of the front axle wheels. According to the company, the combine harvesters are equipped with the widest feeder house on the market $(1720 \mathrm{~mm})$. The threshing and separating device is two-rotor with a receiving beater. To improve grain separation, together with the standard threshing elements, fingers are additionally used in the separation zone of the rotors. The rotation speed of the rotors is from 300 to $1300 \mathrm{~min}-1$. The Dyna-Flo XL cleaning system is $36 \%$ larger in size than the previous S series, with an area of $6.97 \mathrm{~m} 2$. The cleaning capacity is increased by $45 \%$ with a turbine fan. The capacity of grain unloading from the hopper for the X9 1000 is $159 \mathrm{l} / \mathrm{s}$, for the X9 $1100-187 \mathrm{l} / \mathrm{s}$, and the unloading time for both models is 1.5 minutes. To improve power transmission and increase belt life, the drive uses larger pulleys and longer belts. The design of the hinged frame of the header ensures that the field terrain is copied and the height of the stubble cut is constant. The $3.68 \mathrm{~m} 3$ combine harvester cab is equipped with heating, ventilation and a built-in massager in the seat. There are three options for its equipment to be chosen from: Select, Premium and Ultimate. The X9 series combine harvesters provide a significant increase in productivity and harvesting efficiency thanks to one of the widest feeder house housings, an optimized plant feed system, an increased threshing and active separation area, as well as a larger cleaning system area, while maintaining a transport width of less than 3.5 $\mathrm{m}$ in both wheeled and tracked versions. According to the John Deere company, the productivity of combine harvesters reaches 100 tons of wheat per hour with grain losses of less than $1 \%$.

It is increasingly difficult to increase the productivity of combine harvesters with a key straw rack by increasing the size of the threshing and separating units due to the limitations of the installation space and, in particular, the machine width. Thanks to the Aps Synflow Walker threshing and separating device (Fig. 2), the Lexion 6000 series combine harvesters of the Claas company have reached a new level of threshing and separation efficiency [6].

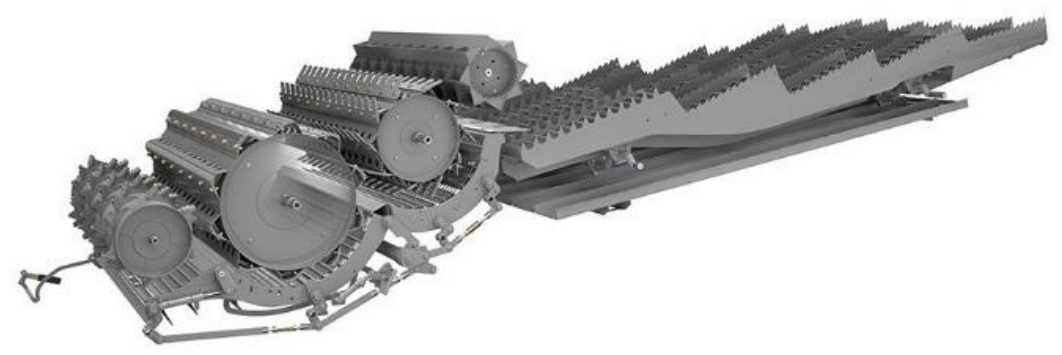

Fig. 2. Aps Synflow Walker threshing and separating device.

The threshing and separating device in these combine harvesters has a width of $1700 \mathrm{~mm}$. Its design includes a pre-acceleration drum with a diameter of $450 \mathrm{~mm}$, a $755 \mathrm{~mm}$ threshing drum with ten sub-rasps and an additional separation drum with a diameter of $600 \mathrm{~mm}$, installed immediately behind the threshing drum. Then comes the reversible drum. The angle 
of contact of the threshing drum with the sub-drum is $132^{\circ}$, the separating drum - $116^{\circ}$. Such angles of contact and synchronized speed of drums rotation provide a uniform and gentle effect on the grain mass flow. The grain mass goes more directly, with less effort applied, which saves fuel. The overload protection system prevents the drums from being clogged with mass. Activation and adjustment of the deck valves and pivot arms are carried out hydraulically using the CEBIS terminal, which allows quick system adjustment to work with any crop or in changed harvesting conditions. The deck configuration is integrated into the Cemos Automatic system, and maintenance or replacement can be carried out from the side of the combine harvester.

The Lexion 7000 and Lexion 8000 series of combine harvesters use the APS Synflow Hybrid threshing system and the Roto Plus rotary straw separator, which consists of two rotors rotating in opposite directions. The APS Synflow Hybrid threshing device consists of an accelerator drum (diameter $450 \mathrm{~mm}$ ) with a sub-drum, a main threshing drum $(755 \mathrm{~mm})$ and a rear beater $(600 \mathrm{~mm})$ that feeds the mass to a two-rotor straw separator. The principle of the APS Synflow Hybrid operation is similar to the principle of operation of the threshing system of the Lexion 5000 and Lexion 6000 series combine harvesters. The accelerator drive, the threshing drum, the rear beater is performed through the central variator. When the speed of the threshing drum changes, the speed of the accelerator and the beater changes synchronously. The rotors of the straw separator are located eccentrically, their diameter is $445 \mathrm{~mm}$, their length is $4200 \mathrm{~mm}$. The combine harvesters of Lexion 7000 and Lexion 8000 series with a rotary straw separator can be equipped with the Claas $4 \mathrm{D}$ grain cleaning system. It allows to fully use their performance and capabilities when moving in the longitudinal and transverse directions on the slope, eliminating the one-way loading of the grain board, the preparatory bottom and the cleaning sieves. It includes a control system for the separation rotor valves and an automatic control system for the cleaning fan.

Another innovative development implemented in Lexion grain combine harvesters is the CEMOS AUTO CHOPPING system of automatic adjustment of straw chopper. During threshing, this system continuously analyzes the moisture level and the volume of straw on the inclined conveyor and accordingly corrects the position of the shear bar and the grating bottom of the chopper. This saves up to $10 \%$ of diesel fuel. In the CEBIS terminal, the machine operator, at its discretion, sets only the mode that the system should follow: the quality of grinding or maximum productivity.

The silver medal of the exhibition was awarded to the New Holland company for innovations in the design of the four-drum threshing device of the CX series combine harvesters. The new design of the Ultra-Flow ${ }^{\mathrm{TM}}$ threshing drum with a diameter of $750 \mathrm{~mm}$ with the pasps offset relative to each other provides a smoother flow characteristic of the harvested crop, which leads to a reduction in power consumption by $16 \%$, an increase in productivity by $10 \%$, a reduction in the number of clogging of grain mass and noise in the cabin, creating a more comfortable working environment for the operator. The rasps of the threshing drum with a polyurethane coating allow to significantly improve the grain quality (34\% less damage). Now operator can remotely control and continuously change the gap between the rotary separator and the Multi-Thresh ${ }^{\mathrm{TM}}$ drum in the range of 20-60 mm from the cab [7].

With an increase in the width of the combine harvester headers, the speed of harvesting, the requirements for the mechanical drive of the header blades increase. Until now, mowing was carried out at a constant speed of the header knife drive, and the defects that occurred during this process were determined by the noise or even by the clogging of the knives. The Gebrüder Schumacher company has integrated angle and torque sensors into the knife drive, 
which can serve as an input signal for adjusting the thresher loading and provide early detection of damage to the knife bar [1].

Gomselmash OJSC presented at the exhibition a grain combine harvester "Palesse GS $4218 \mathrm{CNG}$ ", equipped with a Cummins engine with a capacity of $257 \mathrm{~kW}$, the first in the world running on compressed natural gas [8]. It is equipped with eight ultralight carbon fiber cylinders with a capacity of about $450 \mathrm{~m} 3$ of gas. They provide the combine harvester with continuous operation without stopping for refueling for 8-10 hours. It takes 15 minutes to fully refuel them. According to Gomselmash OJSC, the use of natural gas as fuel can reduce emissions of toxic substances into the environment by 2-3 times and reduce fuel costs by $40 \%$. This eco-friendly model meets the Stage V European requirements.

\section{Conclusions}

The analysis performed showed that the engine power of the most high-performance combine harvesters reached $581 \mathrm{~kW}$. According to the toxicity of exhaust gases, they meet modern requirements. Their design increasingly uses SCR selective catalytic reduction technology. It allows to reduce the emissions of toxic substances into the environment by 2-3 times and reduce fuel costs by $40 \%$, as well as the use of natural gas as fuel. To increase the efficiency of combine harvesters, threshing devices, systems for separation, cleaning, loading of the thresher and process control, working bodies and systems of headers and shredders are being improved.

\section{References}

1. Trends in threshing crop harvesting process technology, URL: https://www.agritechnica.com/en/press/downloads (2020)

2. V.Ya. Goltyapin et al., Innovative technologies and agricultural machinery abroad, 172 (Moscow, FSBSI Rosinformagrotech, 2020)

3. V. Goltyapin, I. Golubev, E3S Web of Conferences. Key Trends in Transportation Innovation. - KTTI 2019, 01013 (2020)

4. Fendt Ideal., URL: https://www.fendt.com/de/maehdrescher/ideal-highlights (2020)

5. D.S. Long, J.D. McCallum, Precision Agriculture 16(5), $492-504$ (2015) DOI: 10.1007/s11119-015-9391-z.

6. Führend in Europa, gebaut in Deutschland - Mähdrescher von CLAAS, URL: https://www.claas.de/produkte/maehdrescher (2020)

7. $\mathrm{CH}$ Mähdrescher, URL: https://agriculture.newholland.com/eu/de$\mathrm{de} /$ maschinen/produkte/mahdrescher/ch (2020)

8. Combine harvester KZS-4118K "Palesse GS4118K, URL: https://www.gomselmash.by/produktsiya/zernouborochnye-kombainy/kzs-4118kpalesse-gs4118k/ (2020) 